\title{
A presença da morte em As Troianas de Sêneca
}

\author{
ZELIA DE ALMEIDA CARDOSO \\ Departamento de Letras Clássicas e Vernáculas \\ Faculdade de Filosofia, Letras e Ciências Humanas \\ Universidade de São Paulo
}

\begin{abstract}
RESUMO: O presente ensaio analisa o enfoque especial dado à morte em $A s$ troianas, de Sêneca, e discute três dicotomias: lamentação $X$ louvação da morte; aniquilamento da alma $X$ sobrevida no Hades; sacrifício humano $X$ assassínio. Após a análise são apresentadas as conclusões a que se chegou. PALAVRAS-CHAVE: Morte, sobrevida, lamentação, aniquilamento da alma, sacrifício humano.
\end{abstract}

O exame de As troianas, de Sêneca, leva o leitor atento a refletir sobre o enfoque particular dado à morte $\mathrm{e}$, talvez, a formular algumas questões a esse respeito. A tragédia é instigante por apresentar aspectos aparentemente contraditórios que merecem uma análise cuidadosa e pormenorizada. Salientamos três desses aspectos e definimos, portanto, três indagações preliminares, a partir das quais alinharemos nossas reflexões: 1) A morte deve ser lamentada, por acarretar sofrimento, ou exaltada, por corresponder a uma libertação? 2) Após a morte as almas se reduzem a nada ou se estabelecem no Hades, podendo fazer incursões pelo mundo dos vivos? 3) A morte de Políxena e a de Astíanax podem ser enquadradas na categoria de sacrificiais ou são meros assassínios, com alguma coloração política?

A primeira pergunta exige uma investigação sobre o conteúdo das duas primeiras partes da tragédia - o prólogo e o párodo.

O prólogo é recitado por Hécuba. As primeiras palavras da rainha mostram, de forma dramática, o desalento que a invade ao contemplar a catástrofe que se abateu sobre a cidade, a inconstância da sorte, a insegurança dos seres e as dimensões da ruína. Os versos são patéticos e a presença de consoantes dentais que se atropelam revela, fisicamente, o entrecortar-se da voz:

Quicumque regno fidit et magna potens

dominatur aula nec leues metuit deos

animumque rebus credulum laetis dedit, me uideat et te, Troial ${ }^{l}$ (Tro.1-4).

("Todo aquele que confia em sua realeza e exerce o poder em um grande palácio, e não teve receio dos deuses inconstantes e se entregou de espírito crédulo a coisas alegres, que me veja a mim e a ti, Tróia") ${ }^{2}$.

Hécuba e a cidade são símbolos eloqüentes da destruição. A rainha aviltada, escravizada, oprimida em sua triste senectude, prestes a ser entregue como prêmio ao astucioso e mentiroso 

em As Troianas de Sêneca.

Ulisses, simboliza a morte da alegria, da juventude, da majestade, da dignidade; Tróia, esmagada e demolida, representa o fim das coisas materiais, dos objetos de cultura feitos pelo homem. No retrato da cidade devastada, os próprios signos verbais empregados por Hécuba evocam a derrocada: caiu por terra, derrubado, o baluarte da Ásia poderosa (6-7)33; Pérgamo tombou sobre si mesmo (14); queimadas as casas, os ornamentos da alta muralha jazem amontoados no chão (16); o dia, como que escurecido por densa nuvem, está envolto em negrume por causa das cinzas de Tróia (20-21).

Tudo isso, entretanto, é mero simulacro da destruição maior, concretizada na perda da vida. Foram inúmeros os que pereceram na guerra, distinguindo-se entre eles, pela própria posição que ocupavam, Príamo, o velho rei, e Heitor, o herdeiro do trono. Príamo representava a tradição e o poder e foi a vítima indefesa de um crime sacrílego que a todos espantou e surpreendeu pelo inusitado das circunstâncias que o envolveram. Heitor era a juventude viril, na plenitude da força, era a esperança de continuidade e o futuro de Tróia.

Hécuba fala de suas lembranças e termina o prólogo convidando as mulheres de Tróia a entoar um canto fúnebre que fosse marcado pela saudade e pela dor.

O párodo se inicia com a lamentação solicitada. Diferentemente do que ocorre com outros cânticos corais presentes nas tragédias de Sêneca, que têm constituição de poemas líricos pelas características e pelos metros empregados, o párodo de As troianas se assemelha aos coros gregos. Configura-se como diálogo e apresenta forma estrófica. Hécuba opera como corifeu, dirige-se às mulheres e estas respondem à rainha, acatando as ordens que lhes são dadas.

Choram inicialmente Heitor e cumprem o ritual fúnebre soltando os cabelos, cobrindo o rosto de cinza, lacerando braços e peitos e gemendo em alta voz (98-128). Acrescentam aos ritos um novo elemento: por ordem de Hécuba desnudam os seios, como a provar que o pudor já não é mais necessário para quem vai entregar-se à servidão.

Choram Príamo, em seguida (129-140), lamentando os sofrimentos suportados pelo rei e a crueldade do assassínio que o vitimou. Até esse momento a morte é apresentada como um fato doloroso, digno, portanto, de ser pranteado com a devida intensidade. Subitamente, porém, Hécuba modifica o tom de seu discurso, sustando a lamentação. Príamo não deve ser objeto de lágrimas e tristeza. Apesar de assassinado com requintes de crueldade, sua morte equivaleu a uma libertação e deve ser exaltada por todos. A mesma voz, que incitara as mulheres a chorar, agora as incita a proclamar a felicidade do velho rei:

... felix Priamus!

dicite cunctae: liber manes

uadit ad imos, nec feret unquam

uicta Graium ceruice iugum (143-146).

(“... feliz Príamo! dizei juntas. Livre ele se dirige às profundezas dos manes e jamais suportará o jugo grego sobre a vencida cerviz").

A exaltação prossegue com o coro das troianas que falam da paz de que Príamo estaria desfrutando nos campos elísios, entre as almas piedosas dos bons.

Como explicar a súbita mudança de Hécuba?

Embora a vida cotidiana possa oferecer exemplos semelhantes de pessoas que se desesperam num primeiro momento de dor para, logo depois, tentar encontrar a própria consolação, o texto de Sêneca, nesse passo, apresenta nítida influência estóica. O desespero, que corresponde a um triunfo das paixões sobre a razão, acaba sendo vencido por esta, num procedimento quase didático. É a atitude que se espera das pessoas sábias; é o comportamento preconizado pelo estoicismo para o qual os sentimentos apaixonados devem ser coibidos para não desencadearem o desequilíbrio da ordem universal, acarretando conseqüências desastrosas. 
Em algumas outras oportunidades, em suas obras filosóficas, Sêneca se vale da doutrina estóica para consolar pessoas de seu conhecimento por perdas sofridas, evocando, como Hécuba $\mathrm{e}$ as troianas, a felicidade futura ou a libertação. $\mathrm{Na}$ Consolação a Márcia, dirigida a uma dama de Roma que perdera o filho, o filósofo se refere ao caráter libertador da morte e à tranqüilidade de espírito de que desfruta quem morreu:

"O teu filho ultrapassou os limites dentro dos quais se é escravo, uma grande e infinita paz o acolheu" (Cons. Marc. XIX, 6) $)^{4}$.

A aparente incoerência no discurso da rainha não existe, pois, como defeito de composição. Ao contrário, tudo parece indicar que, mais uma vez, Sêneca se valeu do texto literário como o meio adequado para veicular idéias estóicas, retratando, para esse fim, um tipo de comportamento bastante usual.

Em outros momentos da tragédia, a relação morte/liberdade volta a surgir. No segundo episódio, quando Andrômaca se despede de Astíanax, ela o exorta a partir para o sacrifício, integrando-se aos troianos que se libertaram pela morte:

I, uade liber, liberos Troas uide (791).

("Vai, vai em liberdade e contempla os troianos livres").

No terceiro episódio, Hécuba aconselha Políxena a rejubilar-se, uma vez que, morrendo, se subtrairá à escravidão, e fala da inveja que suscitará nas mulheres nobres, prestes a transformarem-se em servas dos gregos:

Laetare, gaude, nata. Quam uellet tuos

Cassandra thalamos, uellet Andromacha tuos (967-968).

(“Alegra-te, rejubila-te, minha filha! Como Cassandra, como Andrômaca desejariam teu casamento!")

No êxodo, finalmente, após ouvir o relato fúnebre do mensageiro, a velha rainha reclama pela morte que custa a chegar:

... Sola mors uotum meum,

infantibus uiolenta uirginibus uenis,

ubique properas, saeua: me solam times

uitasque, gladios inter ac tela et faces

quaesita tota nocte, cupientem fugis (1171-1175).

("Ó Morte, tu que só vens violenta para as crianças e para as virgens, este é o meu voto: que venhas cruel por toda parte. Temes apenas a mim, evitas-me. Quando eu te procurei, durante uma noite inteira, entre as espadas, as armas e as flechas inflamadas, fugiste de quem te desejava").

A morte, almejada e buscada com insistência, se afigura como a última solução, a única forma capaz de extinguir os duros sofrimentos impostos pela derrota, dos quais a escravidão é sem dúvida o maior.

Mas passemos à segunda dicotomia anteriormente mencionada. Como justificar a presença de um coro, que fala do retorno das almas ao puro nada após a morte, numa tragédia em que toda a trama decorre do pressuposto desejo de uma "aparição"?

A questão tem intrigado os estudiosos do assunto. Analisemos, pois, o primeiro estásimo de As troianas, no qual se encontram idéias de fundo epicurista no que diz respeito à natureza da alma, para em seguida apresentarmos nossa posição diante do problema. 
O cântico em questão é bastante curto, compondo-se de trinta e oito versos, dos quais nos interessam sobremodo os onze primeiros e os doze últimos, que se equilibram numa simetria quase perfeita.

Nos primeiros onze versos as mulheres falam de suas dúvidas e se questionam quanto à existência de uma pós-vida:

\author{
Verum est an timidos fabula decipit \\ umbras corporibus uiuere conditis? \\ Cum coniunx oculis imposuit manum \\ supremusque dies solibus obstitit \\ et tristis cineres urna cohercuit, \\ non prodest animam tradere funeri \\ sed restat miseris uiuere longius? \\ An toti morimur nullaque pars manet \\ nostri, cum profugo spiritus halitu \\ immixtus nebulis cessit in aera \\ et nudum tetigit subdita fax latus? (371-381).
}

("É verdade que as almas vivem, depois de enterrados os corpos? Ou será apenas uma fábula que ilude os temerosos? Quando um cônjuge fechou os olhos do outro, o dia derradeiro lhe arrebatou o sol e a urna fúnebre recebeu suas cinzas, será que de nada vale entregar a alma ao funeral mas que resta ao infeliz viver por mais tempo ainda? Ou morremos inteiramente e nada sobra de nós quando o espírito se perde no ar com o último suspiro, misturado às névoas, e a tocha sotoposta nos toca o flanco nu?")

No fim do canto, após algumas considerações explicativas, chegam à conclusão que a tantos surpreendeu:

Post mortem nihil est ipsaque mors nihil
uelocis spatii meta nouissima;
spem ponant auidi, solliciti metum:
tempus nos auidum deuorat et chaos.
Mors indiuidua est, noxia corpori
nec parcens animae: Taenara et aspero
regnum sub domino limen et obsidens
custos non facili Cerberus ostio
rumoris uacui uerbaque inania
et par sollicito fabula somnio.
Quaeris quo iaceas post obitum loco?
Quo non nata iacent (397-408).

("Depois da morte nada mais existe e a própria morte nada mais é que a meta suprema de uma corrida veloz. Que os gananciosos aí deixem a esperança e os tímidos o medo. O tempo guloso nos devora e, com ele, o Caos. A morte é indivisível: destrói o corpo e não poupa a alma. O Tênaro, reino de um senhor inflexível, Cérbero, o guarda que bloqueia a soleira de uma porta hostil, são palavras inofensivas, de som vazio, miragens iguais às do sono agitado. Queres saber em que lugar jazerás após a morte? No lugar em que jazem os seres que não nasceram").

Léon Herrmann ${ }^{5}$, responsável pela edição das tragédias de Sêneca publicadas pela Société d'Édition "Les Belles Lettres", refere-se à grande beleza do canto epicurista e lembra que fora bastante criticado por estudiosos de todos os tempos 6 "por estar inserido entre a aparição de Aquiles e o relato da de Heitor". Não encara com estranheza, contudo, o canto em questão, uma 
vez que, para ele, o desespero das troianas seria responsável pelas idéias que expressam e não a adesão consciente a uma doutrina anacrônica.

Nossa opinião sobre esse assunto é diferente. O teor do canto, apesar de "moderno" como diz Léon Herrmann, não nos parece incoerente com as mencionadas "aparições" pelo simples fato de que não há no texto nenhuma evidência de que elas tenham sido "reais".

Explicamo-nos. A primeira "aparição" é descrita por Taltíbio. O arauto grego, dirigindo-se às troianas, imediatamente após o párodo, relata-lhes a "visão" que tivera: o sol acabara de tocar os cumes das montanhas quando a terra estremeceu, fendeu-se com um ruído surdo e permitiu ao espírito de Aquiles que deixasse por um momento as sombras do inferno e se dirigisse ao mundo dos vivos para fazer uma exigência surpreendente e cruel: a imolação de Políxena sobre seu túmulo?.

Embora tal exigência passe a ser o móvel da tragédia, pois que toda a ação dela vai decorrer, a "aparição" se afigura estranha e problemática. O leitor atento poderia formular-se, com razão, uma série de perguntas sobre o fato, sem encontrar, no texto, resposta para nenhuma delas. A primeira indagação haveria de referir-se provavelmente à percepção do terremoto descrito pelo arauto: por que ninguém ouviu o "imenso fragor" ou sentiu o estremecimento da terra?

Disse Taltíbio às troianas:

... Summa iam Titan iuga stringebat ortu, uicerat noctem dies, cum subito caeco terra mugitu fremens concussa, totos traxit ex imo sinus; mouere siluae capita et excelsum nemus fragore uasto tonuit et lucus sacer; Idaea ruptis saxa ceciderunt iugis. Nec terra solum tremuit: et pontus suum adesse Achillem sensit ac strauit uada $\left(170^{\text {bis }}-177\right)$.

("...O sol nascente já tocara os mais altos cumes das montanhas e o dia acabara de vencer a noite quando a terra sacudida, convulsionando-se com súbito rugido surdo, revolveu todas as suas entranhas, desde as mais íntimas profundezas; as árvores agitaram as copas, o bosque elevado e a floresta sagrada ressoaram com imenso fragor: desprenderam-se rochas do Ida, solapadas as bases. E não foi só a terra que tremeu; também o mar percebeu que Aquiles estava de volta e alastrou suas vagas").

O terremoto violento e ruidoso deveria obrigatoriamente ter sido percebido por alguém mais.

Perguntamo-nos em seguida: de que modo Aquiles, um simples herói e não um deus, teria tido condições de escapar do inferno para formular exigências? Como explicar que um morto pudesse exigir um sacrifício humano em sua própria honra, condicionando-lhe a presença de ventos necessários à movimentação da armada? Por que o espectro teria aparecido a Taltíbio, mero porta-voz das ordens do rei? Que estaria fazendo o arauto ao raiar da manhã no bosque sagrado (lucus sacer) de Tróia?

Nenhuma das perguntas pode ser respondida satisfatoriamente. Tudo parece indicar que a "aparição" de Aquiles foi "criada" por alguém.

Talvez a própria constituição formal do primeiro episódio possa sugerir uma explicação para justificar tal hipótese, fornecer uma pista para defender a suposição.

Diferentemente do que costuma ocorrer nas tragédias de Sêneca, o primeiro episódio de As troianas é dividido em duas partes distintas. Na primeira, constituída de uma única cena, Taltíbio se dirige às mulheres e fala da "visão" que tivera. Há em seguida um total esvaziamento 
de palco - o que é muito raro no desenrolar da ação dramática - iniciando-se, a seguir, a segunda parte, dividida em duas cenas: na primeira dialogam Pirro e Agamêmnon; na segunda, Agamêmnon e Calcante.

O diálogo travado entre Pirro e Agamêmnon é intimamente conectado com o discurso de Taltíbio. Pirro exige que se cumpra o desejo de Aquiles; Agamêmnon reluta em autorizar tal cumprimento. A discussão se torna acirrada, os argumentos descambam do tom moralista e político para o meramente pessoal e o rei de Micenas recua em sua posição, mandando chamar Calcante. No segundo diálogo, composto de duas falas apenas, Agamêmnon pede ao vate que anuncie as ordens de Apolo em relação ao sacrifício de Políxena; Calcante não só confirma a exigência de Aquiles como ainda acrescenta mais uma: o sacrifício de Astíanax.

O diálogo entre Pirro e Agamêmnon é bastante sintomático. O jovem, à medida que a discussão progride, mostra a superioridade de Aquiles em relação a Agamêmnon e, por sair-se vitorioso da contenda, acaba por mostrar sua própria superioridade. O sacrifício de Políxena se reveste, pois, de uma significação especial. O holocausto a ser oferecido a Aquiles, comprova a supremacia do herói e acena para sua divinização. Pirro humilha Agamêmnon, quebrando-lhe a autoridade, exigindo-lhe a prática de algo que fere frontalmente suas convicções e relembrando, uma por uma, todas as ocorrências da guerra em que o rei se mostrou fraco e vulnerável e todas as vilezas e crimes praticados pelo clã de Pélope. A atitude de Pirro faz pensar que talvez tivesse sido ele o mentor da história da "aparição", criada com a finalidade de exaltar Aquiles e relegar Agamêmnon a uma posição inferior, e que nessa montagem o jovem de Ciros teria contado com a colaboração de Taltíbio e Calcante e, mais do que provavelmente, com a de Ulisses.

De qualquer maneira, a "aparição" de Aquiles não é comprovada e o relato de Taltíbio não resiste a uma análise mais profunda.

Completamente diferente é a "aparição" de Heitor a Andrômaca. A viúva do herói, dirigindo-se a um ancião, no segundo episódio da tragédia, diz claramente que sonhara com o esposo morto:

... exterret animum noctis horrendae sopor (436).

("O sonho de uma noite horrenda amedronta meu espírito").

A descrição do sonho é minuciosa, pormenorizada; Andrômaca se detém nas circunstâncias, procurando ser precisa e objetiva:

Partes fere nox alma transierat duas

clarumque septem uerterant stellae iugum;

ignota tandem uenit afflictae quies

breuisque fessis somnus obrepsit genis,

si somnus ille est mentis attonitae stupor,

cum subito nostros Hector ante oculos stetit (438-443).

("A noite revitalizadora ultrapassara quase duas partes de seu percurso e as sete estrelas haviam feito voltar seu carro luminoso; uma tranqüilidade desconhecida apoderou-se de minha alma aflita e um curto sono deslizou sobre minhas pálpebras - se é que é sono aquele torpor da mente fatigada - quando, de súbito, Heitor apareceu ante meus olhos").

A aparição, tal como é descrita, tem todas as características do que, na categoria dos êidola, J.P. Vernant designa por óneiros (Vernant, 1973, p. 269) ${ }^{8}$. É simplesmente uma imagem de sonho. Revela-se intangível, transforma-se em fumaça quando a esposa procura tocá-lo e traz o semblante desfeito, cansado, enfermiço. Aconselha a mulher a proteger o filho mas é impotente e ineficaz em seus conselhos. Parece ser uma presença querida mas se revela apenas como uma 
ausência irremediável, um sopro, uma sombra. Andrômaca percebe que o que viu não é um espírito propriamente dito, mas, sim, uma imagem onírica; sabe que os mortos não podem sair do inferno muito embora a crença popular o admita. Daí o fato de procurar atemorizar os soldados gregos, que se preparam para derrubar o túmulo de Heitor, fingindo que está vendo o fantasma do esposo:

... arma concussit manu:

iaculatur ignes: - cernitis, Danai, Hectorem?

An sola uideo? (683-685).

(“... ele agitou as armas com as mãos; está lançando chamas. Vedes Heitor, dânaos? Ou só eu o vejo?")

Mais uma vez se confirma o que antes foi sugerido. As aparições não são reais. A de Aquiles, sobre a qual voltaremos a insistir, parece ter sido mero pretexto para a última crueldade dos gregos; a de Heitor foi um sonho, uma ilusão portanto, muito freqüente em circunstâncias tais como as que Andrômaca enfrentava. O próprio Lucrécio, epicurista por excelência, após ter demonstrado, por numerosos argumentos, que a alma é material e perecível, admite as visões noturnas que aterrorizam as pessoas, procura explicá-las com a teoria dos $\operatorname{simulacra}^{9}$ e afirma após a explicação:

“...muitas vezes as imagens nos arrancaram do sono de forma assustadora, quando estávamos repousando; não creiamos, porém, que são almas que fugiram do Aqueronte ou sombras que esvoaçam entre os vivos, nem que depois da morte algo de nós possa sobreviver já que o corpo e a alma perecem simultaneamente e se dispersam em seus elementos" (Luc. R.N.IV, 40-45) ${ }^{10}$.

Não existe, portanto, no que diz respeito à questão analisada, nenhuma incoerência no texto de As troianas.

Isto posto, passemos ao exame da terceira dicotomia por nós formulada, procurando responder à indagação proposta: a morte de Políxena, bem como a de Astíanax, podem ser consideradas como exemplos de mortes sacrificiais ou foram meros crimes de guerra?

Ao negarmos a aparição de Aquiles e a exigência por ele apresentada, estamos negando simultaneamente o caráter sacrificial da imolação de Políxena e pondo em dúvida as palavras de Calcante, que interpretara a vontade de Apolo, exigindo o sacrifício do menino.

Temos a nosso favor o próprio discurso de Agamêmnon, ao iniciar sua discussão com Pirro. Na pergunta incisiva que endereça ao filho de Aquiles, percebemos nitidamente a indignação do rei:

Quid caede dira nobiles clari ducis aspergis umbras? (256-257)

("Por que desejas salpicar com o sangue de uma imolação nefasta a nobre sombra de um chefe ilustre?")

Depois de longa exposição sobre o sentido do poder, Agamêmnon exprime sua vontade real, negando a permissão para o sacrifício reclamado, por considerá-lo criminoso:

...Regia ut uirgo occidat

tumuloque donum detur et cineres riget

et facinus atrox caedis ut thalamos uocent,

non patiar $(287-290)$.

("Não permitirei que uma virgem real morra e seja oferecida como prêmio a um 
túmulo e regue com seu sangue as cinzas de um morto e que chamem de casamento ao crime atroz de um assassínio").

E ao responder à pergunta de Pirro sobre se Aquiles nada receberia em recompensa dos trabalhos, acrescenta de forma ainda indignada mas, ao mesmo tempo, ponderada:

\section{Ferent et illum laudibus cuncti canent magnumque terrae nomen ignotae audient. Quod si leuatur sanguine infuso cinis, opima Phrygii colla caedantur greges fluatque nulli flebilis matri cruor. Quis iste mos est, quando in inferias homo est impensus hominis? Detrahe inuidiam tuo odiumque patri, quem coli poena iubes. (293-301)}

("Receberão e todos o celebrarão com louvores e as terras desconhecidas ouvirão seu grande nome. Se as cinzas devem ser reconfortadas com sangue derramado, os rebanhos da Frígia, de gordas cervizes, serão imolados e o sangue correrá sem que mãe alguma precise chorar. Que costume é este e em que tempo um ser humano foi sacrificado a outro? Poupa hostilidade e ódio a teu pai para quem exiges a homenagem de uma punição").

A situação se altera com o prosseguimento da discussão. Como vimos, embora tivesse negado veementemente permissão para o cumprimento de um suposto desejo de Aquiles, considerando a imolação da virgem como crime hediondo, Agamêmnon perde terreno diante dos argumentos de Pirro, hesita e acaba por chamar Calcante, que confirma a exigência.

Passamos a discutir; então, a validade e a veracidade do oráculo. Léon Herrmann" (Herrmann, 1924, p.410), em seu alentado estudo intitulado Le théâtre de Sénèque, procura mostrar que Agamêmnon cedeu a Pirro movido pela religiosidade. Pelo texto da tragédia, entretanto, não se tem a impressão de que os oráculos sejam respeitados como expressão da vontade divina.

Do mesmo modo que as aparições dos mortos são postas em dúvida no correr das cenas, também se duvida dos oráculos.

Quando Ulisses vai buscar Astíanax, que se escondera no túmulo do pai, embora se apresente a Andrômaca na condição de intermediário de Calcante e procure reforçar as palavras do adivinho, mostra claramente que a morte do menino tem conotação política:

Et si taceret augur haec Calchas, tamen dicebat Hector cuius et stirpem horreo (534-535).

("E se o adivinho Calcante se calasse, Heitor, por cuja estirpe me amedronto, o diria").

Mais adiante, ao perceber que Andrômaca escondera o filho e simulara que morrera, e desejando intimidá-la, Ulisses não hesita em “criar" um novo oráculo, para justificar a demolição do túmulo do guerreiro, que substituiria, segundo ele, o frustrado sacrifício de Astíanax:

Lustrale quoniam debitum muris puer

sacrum antecessit nec potest uatem sequi

meliore fato raptus, hoc Calchas ait

modo piari posse redituras rates,

si placet undas Hectoris sparsi cinis

ac tumulus imo totus aequatur solo (634-639).

("Uma vez que o menino antecipou o sacrifício expiatório reservado aos muros e, 
arrebatado por um destino melhor, não pôde satisfazer ao vaticínio, diz Calcante que os navios que vão partir só podem ser purificados se as cinzas de Heitor, espalhadas, aplacarem as ondas e se todo o túmulo for arrasado, até os alicerces").

A atribuição de tais ordens a Calcante é pura invenção de Ulisses - mais uma das artimanhas do "homem das mil astúcias", capaz de empregar todos os meios para atingir o fim desejado. Se, portanto, não havia um oráculo exigindo a destruição do túmulo e o lançamento das cinzas no mar, e se Ulisses dele fala com tanta convicção e desenvoltura, por que não se admitir que o primeiro oráculo mencionado também tenha sido uma invenção?

Andrômaca se dá conta da verdade. Quando, mais uma vez, tenta obter a clemência para o menino, alegando que a escravidão já lhe seria um castigo imenso, e Ulisses insiste na determinação de Calcante, ela explode com veemência:
$O$ machinator fraudis et scelerum artifex, uirtute cuius bellica nemo occidit, dolis et astu maleficae mentis iacent etiam Pelasgi, uatem et insontes deos praetendis? Hoc est pectoris facinus tui (750-754).

("Ó maquinador de astúcias e artífice de crimes, por cujo valor bélico ninguém morreu mas por cujas artimanhas e mentiras jazem até mesmo pelasgos! Pretendes culpar o adivinho e os deuses inocentes? Este é um crime de teu coração").

A idéia de crime, e não de sacrifício, volta a aparecer mais adiante, no terceiro episódio e no êxodo. No terceiro episódio, no momento em que Políxena é levada por Pirro, para ser morta sobre o túmulo de Aquiles, Hécuba vê no holocausto um sacrilégio infame e exclama desesperada e furiosa:

... abreptam trahit.

Maculate superos caede funesta deos, maculate manes (1003-1005).

(“... ele a leva, arrastada. Maculai os deuses superiores com este assassínio funesto, maculai os manes").

No êxodo, o mensageiro, ao trazer às troianas a notícia da consumação das mortes, fala inicialmente em crime e não em sacrifício:

Quod tam ferum, tam triste bis quinis scelus Mars uidit annis? (1057-1058)

(“Que crime tão terrível, tão triste, Marte viu durante estes dez anos?")

Andrômaca, por sua vez, ao ouvir a descrição da morte do filho, considera-a como um delito vil que nem os povos mais bárbaros da terra haviam chegado a cometer:

Quis Colchus hoc, quis sedis incertae Scytha

commisit, aut quae Caspium tangens mare

gens iuris expers ausa? Non Busiridis

puerilis aras sanguis aspersit feri

nec parua gregibus membra Diomedes suis

epulanda posuit (1104-1109).

("Que colco, que cita de morada incerta cometeu este crime? Que povo das margens do Cáspio, desconhecedor de leis, ousou isto? Sangue infantil não aspergiu os 
altares de Busíris nem Diomedes ofereceu a seus rebanhos, para serem devorados, membros tão pequenos").

O caráter sacrificial das mortes fica, pois, afastado. Nem Astíanax, nem Políxena foram imolados numa cerimônia religiosa, num ofício ritual. A morte dos dois jovens troianos, segundo o texto, apresenta todas as características de crime, crime de guerra, se assim o quisermos, mas, evidentemente, crime.

Não há incoerências, portanto, na focalização da morte, na tragédia de Sêneca. Dependendo do ângulo em que esteja o contemplador, pode ser considerada como algo lamentável ou digno de exaltação; a observação sobre o aniquilamento da alma não entra em choque com referências ao Elísio ou ao Hades, tomados, como tudo indica, por meras expressões estilísticas; as "aparições" ou parecem ser forjadas - como a de Aquiles -, ou não passam de imagens de sonho - como a de Heitor; as imolações de Astíanax e Políxena, por fim, têm o caráter de assassínios e não de sacrifícios exigidos pelos deuses, estranhos, aliás, às civilizações mais avançadas ${ }^{12}$. Focalizando a morte com tais peculiaridades, tratando-a de forma tão especial no corpo de $A s$ troianas, Sêneca, mais uma vez, mostrou sua capacidade de reelaborar um velho mito com originalidade criativa e de expor sua opinião pessoal a respeito de problemas que envolvem posturas doutrinárias.

\section{Notas}

1- Utilizamos neste ensaio o texto de As troianas estabelecido por Otto Zwierlein e publicado pela Oxford University Press (Cf. Bibliografia).

2 - A tradução dos trechos de As troianas são de nossa responsabilidade (Cf. Cardoso, 1976).

3- Os números entre parênteses correspondem aos versos em que os elementos referidos são evocados.

4 - A tradução do trecho da Consolação a Márcia é de responsabilidade de Cleonice F. M. van Raij (Cf. Sêneca, 1992).

5 - Além de manifestar sua opinião na nota mencionada, Léon Herrmann (Herrmann, 1924, pp. 369-373) também faz uma referência ao caráter epicurista do primeiro estásimo em Le théâtre de Sénèque, obra cuja leitura pelos estudiosos de Sêneca ainda hoje pode ser considerada indispensável. Franco Caviglia (in Seneca, 1981, pp. 48-49), porém, na edição da tragédia publicada pelas Edizione dell' Ateneo, lembra que em As troianas de Eurípides, ao dialogar com Andrômaca, Hécuba dissera que "a morte não é nada", frase que parece servir de mote ao estásimo em questão.

6 - M. Patin, sempre extremamente severo em relação a Sêneca, se situa entre os que criticaram duramente o primeiro estásimo de As troianas (Cf. Patin, M. Études sur les tragiques grecs. Paris, Hachette, 1866. p. 413); Pichon, por sua vez, reprovou a presença de idéias epicuristas numa tragédia em que predomina o tom estóico (Cf. Pichon, R. Histoire de la littératura latine. Paris, Hachette, 1897. p. 546). Na verdade são críticos já distanciados, no tempo, cujas opiniões sobre o texto literário, ainda que aproveitáveis, em grande parte, se baseiam muitas vezes em pressupostos teóricos hoje considerados ultrapassados.

7 - A descrição da figura de Aquiles feita por Taltíbio apresenta particularidades que a distinguem das visões oníricas: aparece à luz do dia, tem estatura elevada, voz forte e faz uma exigência macabra que destruirá a vida de um ser vivente. Em "A categoria psicológica do 'duplo", estudo inserido em Mito e pensamento entre os gregos, Vernant (Vernant, 1973, pp. 263 ss.) considera a psyché (alma) como uma das formas que pertencem à categoria dos 
"duplos". Segundo o autor, admitia-se na Grécia arcaica que, quando um homem morria sem que lhe tivessem sido prestadas honras fúnebres, sua psyché ficava errando e seu espectro encobria uma força perigosa que se manifestava por crueldades em relação aos vivos. Intencionalmente - se tiver realmente querido mostrar que a "aparição" de Aquiles foi uma farsa -, ou por casualidade, Sêneca atribuiu a Aquiles, que havia sido homenageado com pompas funerárias, um modo de agir próprio dos espectros vagantes.

8 - O óneiros, para Vernant (Vernant, 1973, p. 269), é simplesmente uma imagem de sonho inconsistente e impotente. Como a psyché, o phásma (aparição) e a skiá (sombra), o óneiros também pertence à categoria dos "duplos".

9 - Para Lucrécio (R.N. IV, 33 ss.), os simulacra são "como que membranas arrancadas da superfície das coisas", "esvoaçam de um lado para outro, nos ares, e, vindo ao nosso encontro quando estamos em vigília ou dormindo, aterrorizam nossas mentes cada vez que deparamos com figuras espantosas e imagens dos que já não mais vêem a luz".

10 - A tradução do trecho de Lucrécio é de nossa responsabilidade.

11 - Em Le théatre de Sénèque, ao estudar as personalidades de reis e tiranos presentes nas tragédias de Sêneca, Léon Herrmann (Herrmann, 1924, pp 410-411) se detém na análise do comportamento de Agamêmnon e considera que chamar Calcante para decidir foi um ato sábio e coerente com a calma e ponderação do rei.

12 - O sacrifício humano, ou seja, a imolação de pessoas a divindades, foi comum entre germanos, celtas e alguns povos do Oriente (Cf. Challaye, 1962, pp. 167 ss.). Mas não era usual nem na Grécia, onde o sacrifício de Ifigênia é um caso isolado, nem em Roma, onde, conforme diz Propércio (III, xxii, 29 ss.), nenhum fato semelhante a esse jamais ocorrera.

\section{Referências Bibliográficas}

BERNHARD, J. Platon et le matérialisme ancien. Paris: Payot, 1971.

CARDOSO, Z.L.V.A. A construção de As troianas de Sêneca. São Paulo: USP, 1976 (Tese de doutoramento policopiada).

CHALlAYE, F. Pequena história das grandes religiões (Trad. de A. SILVEIRA). São Paulo: IBRASA, 1962.

DURKHEIM, E. Les formes élémentaires de la vie religieuse. Paris: Alcan, 1912.

L. Annaei Senecae Tragoidiae, incertorum auctorum Hercules (Oetaeus), Octauia. Recognouit breuique adnotatione critica instruxit Otto ZWIERLEIN. Oxoniis et Typographes Clarendoniano. MCMLXXXVI.

LEROI-GOURHAN, A. As religiões da pré-história. Lisboa: Ed. Setenta, 1985.

NOVAK, M.G. A natureza da alma no poema de Tito Lucrécio Caro (De rerum natura III). São Paulo: USP, 1985 (Tese de doutoramento policopiada).

ROBERT, F. La religion grecque. Paris: PUF, 1981.

SÊNECA. Cartas consolatórias (Trad. de C.F.M. van RAIJ). Campinas: Pontes, 1992.

SÉNEQUE. Tragédies (Texte ét. et trad. par L. HERRMANN). Paris: .Les Belles Lettres, 1967. 

em As Troianas de Sêneca.

CARDOSO, Z. A. The presence of death in Seneca's Trojan women. Classica, São Paulo, 7/8:153$164,1994 / 1995$.

ABSTRACT: This essay analyzes the particular emphasis given to death in Seneca's Trojan women and discusses three dichotomies: lamentation $X$ praise of death, annihilation of the soul $X$ the soul's afterlife inHades; human sacrifice $X$ murder. After the analysis, the conclusions reached are presented.

KEY WORDS: Death, the soul's afterlife, annihilation of soul, lamentation, human sacrifice. 